\title{
Painel para uma compreensão de história da literatura, ciência da literatura
}

\author{
Maria Aparecida Barbosa ${ }^{1}$ \\ Programa de Pós-Graduação em Estudos da Tradução e em Literatura, Universidade Federal de Santa Catarina, \\ Florianópolis, SC, Brasil
}

Resumo: Procurando se nortear por duas categorias indicadoras: a contemporaneidade investigativa e a extensão do objeto, este artigo, ramo do estudo das resenhas e críticas literárias de Walter Benjamin, se reporta ao artigo Literaturgeschichte und Literaturwissenschaft, publicado em 1931 no jornal Die Literarische Welt, traduzido ao português e editado pela Editora 7Letras em 2016 como História da Literatura e Ciência da Literatura, bem como à resenha escrita em 1931 creditada ao pseudônimo Detlev Holz em 1933 no Literaturblatt do Frankfurter Zeitung sobre o volume 1 da Kunstwissenschaftlichen Forschungen. Desde 2014 o projeto de edição da Nkf - Neue kunstwissenschaftliche Forschungen, empreendida por egressos da Universidade de Viena para o fórum entre pesquisadores estabelecidos e early stage researchers, está se constituindo através da recuperação ou da desconstrução crítica de princípios da revista Kunstwissenschaftlichen Forschungen dos anos 1930, que foi fundada no contexto da "New Viennese School" de História da Arte. Disponível online nas páginas da Universidade de Viena e da Universidade de Heidelberg, essa nova revista publicou os números temáticos Utopien der Moderne, Wiener Schule e Digitalisierung. Com o acréscimo do adjetivo neue (novas), o fórum se filia explicitamente a um debate da metodologia no âmbito da arquitetura, das artes plásticas e de disciplinas afins. Em virtude que se estabelece entre Benjamin e a publicação de Viena, este artigo considera as imbricações metodológicas e, embora parta da teoria e da crítica literária, está aberto às contaminações transdisciplinares e tem da mesma maneira o objetivo de reavaliar metodologias de operar com os textos.

Palavras-chave: Ciência da Literatura; Contemporaneidade; Objeto.

Title: Panel for a history of literature, literature science comprehension

Abstract: Branch of the research concerning Walter Benjamins literary reviews, this article looks forward a orientation throught two categories: the investigative contemporaneity and the extension of the object. It referes to Literaturgeschichte und Literaturwissenschaft, published 1931 in Die Literarische Welt, translated in portuguese and published by Editora 7Letras on 2016 as História da Literatura e Ciência da Literatura, and mainly to the review from 1931 published under the pseudonim Detlev Holz on 1933 in Literaturblatt do Frankfurter Zeitung about the Kunstwissenschaftlichen Forschungen I. Since 2014 the NkfNeue kunstwissenschaftliche Forschungen edition project, undertaken by alumni of the University of Vienna for the forum between established researchers and early stage researchers, is being constituted through the recovery or critical deconstruction of

\footnotetext{
${ }^{1}$ Doutorado em Literatura (Universidade Federal de Santa Catarina, UFSC). Professora da UFSC. Orcid: http://orcid.org/0000-0002-6494-6757

E-mail: aparecidabarbosaheidermann@gmail.com
} 
principles of the Kunstwissenschaftlichen Forschungen of the 1930s, which was founded in the context of the New Viennese School of History of Art. Available online at the University of Vienna and the University of Heidelberg websites, this new magazine has published thematic issues Utopien der Moderne, Wiener Schule and Digitalisierung. With the addition of the adjective neue (new), the forum explicitly refers to a discussion of methodology in the field of architecture, plastic arts and related disciplines. Because of the relation established between Benjamin and the Vienna publication, this article considers methodological overlaps and, although based on literary theory and criticism, it is also open to transdisciplinary contaminations and it has the same objective of reevaluating methodologies of working with texts.

Keywords: Ciência da Literatura; Contemporaneidade; Objeto.

E assim apresentamos o método novo, dialético, de escrever a história: atravessar o ocorrido com a intensidade de um sonho para experimentar o presente como o mundo da vigília ao qual o sonho se refere!

(Primeiro esboço, Passagens, F 6)

O alegorista é por assim dizer o polo oposto ao colecionador.

Ele desistiu de elucidar as coisas através da pesquisa do que lhes é afim e do que lhes é próprio.

Ele as desliga de seu contexto e desde o princípio confia na sua meditação (Tiefsinn) para elucidar seu significado.

(Passagens, 4 a)

\section{Prólogo}

De acordo com a página da Universität Wien, a formação acadêmica de arte naquela Instituição acontecia em seus primórdios por intermédio da abordagem prática e científica em diálogo com as obras e as fontes da história artística. Por isso e pelo espírito inovador, o Instituto de Viena conquistou reputação e renome. Na prática, porém, a pluralidade metódica resultava em perdas decorrentes de atritos agravados por incompatibilidades pessoais, o que, inclusive, levou entre 1911 e 1933 à separação espacial de ambas as cátedras de história da arte em dois institutos rivais. [...] Com isso os métodos comparísticoformalistas passaram a ser confrontados com os intelectuais ou históricos.

Às personagens da revista Kunstwissenschaftlichen Forschungen, criada em 1930 e circulada através de dois números, unia simplesmente o status de egressos do Instituto História da Arte de Viena, faltava-Ihes uma diretriz editorial. Ora o Instituto se tornou uma referência em virtude de toda uma geração de pesquisadores sistematicamente expulsos ou forçados ao exílio nos anos 1930, como Ernst Gombrich, Otto Kurz, Otto Pächt e Fritz Saxl. Mas esses destinos se diferenciavam. Sabe-se que em 1933, com a ascensão do nacionalsocialismo, o contrato de Otto Pächt na Universidade de Heidelberg foi rescindido e pouco antes do Anschluss austríaco, ele teve de deixar Viena pela Inglaterra, ao passo que Hans 
Sedlmayr aderiu ao regime e assumiu a cátedra, então única, do Instituto. Visando a compreensão dessas relações para a tradução da resenha que Benjamin escreveu do primeiro volume da publicação de Pächt, uma revista que contém artigos de autoria do editor, de Sedlmayr, Carl Linfert e G. A. Andreades, os próximos ensaios breves deste artigo procuram em forma de cenas esparsas aproximar-se do campo histórico e teórico. Independente de uma cronologia linear, as cenas correspondem a estágios de leituras que se desenvolvem concomitantemente. A mencionada resenha se reporta ao objeto que permeia as cenas: a obra Kunstwissenschaftlichen Forschungen.

Esses protagonistas - Benjamin, Einstein, Sedlmayr, Alfred Bauemler - configuram um debate relevante e bem mais amplo acerca de estética e política na década de 1930, mesmo quando não se citam ou se mencionam.

\section{Cena I}

Desde que as reflexões de Konrad Fiedler (1977) deslocaram o foco da criação artística da subordinação à representação de objetos do entorno (sob a pressão e $a$ estreiteza da realidade: p. 167) para o viés da expressão do criador, constituindo a partir dessa enunciação fundamentos para uma teoria, a historiografia da arte passa a reavaliar suas leituras e a repensar a disciplina. Em decorrência da definição metodológica da historiografia da arte advêm as delimitações e os estabelecimentos das disciplinas vinculadas: história social da arte, iconografia, história cultural da arte. No direcionamento radical do Naturalismo a atividade artística se insere no grande movimento intelectual que parece separar definitivamente um novo mundo do velho. Certo âmbito da disciplina História da Arte apoia a sua autonomia científica através de um método que privilegia a forma em detrimento do conteúdo da arte, ou seja, abole as qualidades que não podem ser experimentadas visualmente. Os historiadores da arte Heinrich Wölfflin und Alois Riegl, na esteira do que fora iniciado na filosofia estética do Idealismo, empreendem com acentuações distintas a modernização dos conceitos, e com isso contribuem para um deslocamento que se afasta da mimesis artística e se volta para a capacidade produtiva.

\section{Cena II}

Benjamin recebe o primeiro volume da revista Kunstwissenschaftliche Forschungen (edição Otto Pächt), de Linfert, autor de um dos artigos: "Grundlagen der Architekturzeichnung" (fundamentos do desenho arquitetônico) - fls. 133-246, e se manifesta entusiasmado com a publicação numa carta de 18.7.1931, dizendo que o estudo proporcionara chaves significativas para suas próprias indagações. 
De alguma maneira o senhor escovou o passado a contrapelo, de modo que cada fato (obra) se perfila individualmente mas o observador através do individual consegue ver o fundamento comum. Especialmente fascinante foram a meu ver as relações que o senhor reconheceu entre arquitetura e ornamento e, acima de tudo, ao tratar de Delafosse [Louis Remy de la Fosse. 1659 na França; 1726 em Darmstadt] que tão expressivamente apresentou. Uma minha ideia antiga e dileta de que os meados do século XVIII tiveram uma vida intelectual e formal estranha e fechada exatamente como o barroco, só que outra; e subitamente durante a leitura de sua análise de Delafosse se tornou mais que um devaneio, através das páginas abriram-se perspectivas até o templo de Sarastro. Talvez tenhamos um dia desses a oportunidade de conversar sobre nossas afinidades [...] (BENJAMIN, volume III, p. 653)

Ao escrever a resenha "Strenge Kunstwissenschaft" (Rigorosa teoria da arte) Walter Benjamin a inicia com uma referência, incluindo citações, ao prefácio que Wölfflin escreveu em 1898 para A Arte Clássica, livro que experimenta com um gesto lapidar abandonar um modus operandi de empreender historiografia da arte:

O interesse do público moderno [...] parece hoje mais uma vez se voltar propriamente para as questões artísticas. Exige-se de um livro de história da arte não mais a mera anedota biográfica ou a descrição das circunstâncias do contexto, mas quer se inteirar daquilo que perfaz o valor e a substância da obra de arte. [...] O natural seria que toda monografia de historia da arte contivesse também um trecho de Estética. (BENJAMIN, volume III, 3, p. 69)

E mais adiante: Para alcançar com mais segurança esse objetivo se deve acrescentar como ensaio contraposto à primeira parte, histórica, uma segunda mais sistemática. Benjamin indica que essas disposições de Wölfflin apresentam tanto as intenções, como também as limitações das experimentações formalistas, que não teriam vingado totalmente. Wölfflin teria apontado, sim, ao dualismo entre uma história universal rasa da arte de todos os povos e tempos e uma Estética academicista, mas não teria superado essa fragilidade. Se a concepção histórica universal da história das artes (bem como de outros segmentos históricos) tinham prejudicado o estudo sério com o jogo livre na era do ecletismo, um programático debate se contrapunha, para além da história da arte, como Benjamin observa se valendo da constatação de Walter Muschg relativa à literatura.

Hoje em dia a crença no sentido de uma apresentação integral perdeu lugar nas pesquisas do gênero. Ao invés disso se ocupa de figuras e indagações, que na época das histórias universais eram sobretudo designadas lacunas. [...]. O abandono do realismo acrítico da contemplação histórica, o 
esmaecimento das construções macroscópicas constituem as marcas mais importantes da nova pesquisa. (BENJAMIN, volume III, 3, p. 370)

De fato, é nesse sentido de se deter no pormenor que o artigo introdutório de Sedlmayr na revista se aplica ao estabelecimento de princípios que hão de nortear "investigações de figurações isoladas":

A fase da ciência da arte em devir precisará colocar em primeiro plano de uma maneira como até hoje não se viu a investigação de figurações isoladas... Tão logo a obra de arte individual é considerada uma tarefa própria da ciência da arte ainda a ser resolvida, ela está diante de nós em poderosa novidade e proximidade. No passado, mero meio do conhecimento, traço de outra que a partir dela deveria ser aberta, ela aparece agora como um pequeno mundo de uma espécie singular e especial. (BENJAMIN, volume III, 3, p. 370)

A avaliação crítica que Benjamin faz da obra de Wölfflin é acolhida com resistência na redação do Frankfurter Zeitung, conforme Linfert explana em detalhes na carta de 13.12.1932, e o autor foi obrigado a modificar passagens polêmicas da resenha, o que esclarece a delonga para a publicação. Ilustram essas alterações inseridas com a finalidade de fortalecer a confrontação frente ao formalismo de Wölfflin com a de outrem, a menção do obituário que Dvořák dedicou a Riegl.

A resenha reverencia na revista o princípio metodológico de acentuar na análise estética o insignificante (Unbedeutsam), à maneira incomparável com que os Irmãos Grimm no início do século XIX expressaram o espírito da filologia genuína. O pesquisador genuíno seria capaz de apontar nas obras mais autênticas o que as faz sobreviver: o imperceptível (Unscheinbar) ou mesmo o ofensivo (Anstössige) - lembrando que ambos não se contradizem - o que faz emergir o conteúdo substancial (Gehalt).

E considerando sua definição de material, não foi Wölfflin o predecessor desse novo tipo de doutrina de arte, porém Riegl. A investigação de Pächt sobre Pacher é uma nova tentativa daquela grande forma de representação que Alois Riegl tão magistralmente dominou como uma passagem do objeto individual (Einzelgegenstand) em relação à sua função espiritual, especialmente no trabalho sobre os retratos de grupos. (BENJAMIN, volume III, p. 370)

"Kunstgeschichte und Universalgeschichte" (História da Arte e História Universal), de 1898, ilustra o novo método que Riegl propõe, que supera a convencional história universal composta por "Höhepunkten" e "Verfallsperioden" (pontos altos e períodos decadentes), alternando-a com a "ourivesaria" (p. 373), na medida em que o breve estudo de Riegl 
contrapõe a maneira mais antiga do exame histórico-universal a uma interpretação profunda da obra artística específica. Esse método parte do entendimento de que "o teor relevante da obra, tanto mais decisivo será, quanto mais imperceptível (unscheinbarer) e inerente (inniger) estiver ligado ao seu teor coisal (Sachgehalt)". (p. 372)

Benjamin se detém ademais na monografia de Riegl, "Das holländische Porträt" ( $O$ retrato de grupo holandês), que trata de uma série de pinturas provenientes dos séculos XVI e XVII, obras que de modo algum encontravam-se disseminadas homogeneamente pelas províncias holandesas, concentrando-se ora no norte, ora no sul da Holanda, sobretudo em Amsterdã, em Haarlen e em outras cidades. Além da categoria investigativa "ênfase no insignificante", um corpus singular que permitiria uma compreensão bem mais ampla a partir de sua "função espiritual", um valor metodológico adicional legado por Riegl, especialmente no livro Spätrömische Kunstindustrie (Wien 1901), consistia na ênfase à contemporaneidade: à pesquisa destemida nunca faltam as preocupações vivas do seu presente (p. 366). Tanto que a obra de Riegl teria sido capaz de pressentir sinais prenunciadores de forças subterrâneas que somente uma década mais tarde emergiriam com o Expressionismo.

\section{Cena III}

Uma resenha de referência sobre o segundo volume Kunstwissenschaftliche Forschungen, de Meyer Schapiro (1904-1996), é "The new viennese school", que está disponível no JSTOR, review publicada originalmente no Art Bulletin Vol. 18, No. 2, Jun., 1936. Lembrando que essa revista, fundada em 1913, continua sendo editada e é conhecida pelo rigor acadêmico em suas críticas de história da arte. $\mathrm{O}$ autor, Schapiro, era filho de pais judeus ortodoxos que tinham fugido do clima antisemita da Lituânia e se estabelecido nos Estados Unidos em 1907. Foi professor História da Arte na Columbia University de Nova lorque e esteve próximo de escritores e filósofos, entre eles Harold Rosenberg, Clement Greenberg e outros, que eram conhecidos sob a alcunha "New York intelectuals" e de uma maneira ou outra se manifestavam como anti-stalinistas.

$\mathrm{Na}$ resenha, Schapiro é que atribui ao grupo de vienenses, alemães e russos a alcunha de "The new viennese school", que ele coloca como o centro mais avançada de estudo da arte. Demonstra interesse e elogia o espírito inteligente e as assistemáticas e originais observações das monografias apresentadas no volume, mas no decurso deplora as respectivas falta de rigor e mesmo de escrúpulo. O princípio básico recomendado ao estudioso seria antes de mais nada uma abordagem correta do objeto como um todo organizado antes de se propor ao necessário exame das estruturas e relações formais. E na revista, a crítica aponta que a observação das formas se dava como uma ciência independente, sendo as referências aos sentidos e às causas em geral periféricas, altamente 
formalistas e abstratas. Os textos programáticos, apresentados como novas abordagens para a arte ou como correções de metodologias correntes inadequadas, abstinham-se de apresentar as noções teóricas, legando-as às entrelinhas sem sistematica e acurada apresentação. Desfavorável também é o parecer de Schapiro quanto à coerência entre a metodologia propalada e a, de fato, empregada:

Os artigos do livro são relativamente pobres em conclusões históricas positivas. Eles estão interessados principalmente em objetos individuais, os autores tendem a isolar formas das condições históricas de seu desenvolvimento para aproximá-las de constantes míticas, raciais e e psicológicas, ou a lhes conceder uma carreira auto-evolutiva [...] Em vários dos artigos nós nos deparamos com concepções e alusões a qualidades e causas que não temos como verificar, cuja medição e verificabilidade foi deixada ao leitor. (SCHAPIRO 1936, p. 259)

\section{Cena IV}

A revista $N k f$ se manifesta criticamente com relação à ideia de unicidade conceitual do grupo que estava à frente do Instituto no início dos anos 1930: o que está por trás da ideia de "Instituto História da Arte, de Viena"? A indagação que motivou um congresso de 2002 reverbera ainda questionando a força constituída por aquele grupo, fortalecida pelos textos históricos escritos em 1934 por Julius von Schlosser, que teriam como um "monumento de propaganda da ciência" (Monument der Wissenschaftspropaganda) logrado inventar uma tradição à maneira das tradições inventadas de Eric Hobsbawn (conforme o editorial da revista $N k f$ no. 1). Para ilustrar a desconstrução que os jovens pesquisadores da $N f k$ vêm operando frente à essa tradição a revista Linguagem \& Ensino traz neste mesmo número a tradução do artigo de Maria Männig. Acompanhando em sua tese o percurso de Hans Sedlmayr reflete as consequências que da historiografia da arte podem advir.

\section{Cena V}

Foi traduzido ao português e publicado pela Editora 7Letras em 2016 sob o título História da Literatura e História da Literatura a colaboração de Benjamin no contexto de uma série sobre "o estágio hodierno das ciências" do jornal Die Literarische Welt. Após situar a história da literatura como parte da história geral, o ensaio formula a questão se, de fato, a história da literatura seria no final das contas uma disciplina. Apresentando um levantamento de obras de referência do século XIX, mostra que as tentativas de história da literatura em língua alemã de demasiadamente diletantes e ingênuas para a contraposição da relação história e literatura, ou história e história da literatura, passam a espelhos da 
metodologia das ciências naturais, pautando-se por "Sammeln und Hegen" (compilação e conservação). Visando satisfazer um público burguês com um rol de personalidades ilustres, quer estivessem relacionados com a esfera política, literária, religiosa ou filosófica, esse método positivista da história da literatura tinha o objetivo de proporcionar um quadro universal histórico-cultural. O ensaio se coloca categoricamente crítico à essa pretensão totalizadora e às loas heroicizantes, que defendiam a todo o custo valores sociais conservadores - uma tecla recorrente nos ensaios do autor. Em contraposição sugere que a ciência da literatura deveria conferir precedência ao real e constata naqueles meados de 1931 o crescente interesse pela pesquisa literária, mais do que pela criação literária. A par e passo com a matéria atual, com o projeto de Rancière por exemplo, Benjamin frisa a possibilidade de renovação e o incontestável vigor da pesquisa literária no desempenho do ensino e da tarefa didática. Retomando as considerações apresentadas sobretudo no "Ensaio sobre as Afinidades eletivas" em que defende o comentário aliado à averiguação linguística, em História da Literatura e Ciência da Literatura Benjamin reafirma seu postulado de um estudo filológico em que se processe "a interpenetração entre a observação histórica e crítica" (2016, p. 31) nos moldes das origens germanísticas com os Irmãos Grimm. A tarefa da História da Literatura não seria partir da relação da obra literária no contexto do tempo em que ela surge, mas na esfera de sua atuação, de sua tradução, um "micro-aión", em que se apresenta, isso sim, o tempo presente, o hoje que se debruça sobre ela e a reconhece.

\section{Referências}

BENJAMIN, Walter. História da Literatura e Ciência da Literatura. Tradução Helano Ribeiro. Rio de Janeiro: 7LETRAS, 2016.

BENJAMIN, Walter. Origem do Drama Trágico Alemão. Tradução João Barrento. Belo Horizonte: Autêntica, 2013.

BENJAMIN, Walter. Walter Benjamin. Gesammelte Schriften [ed. Rolf Tiedemann e Hermann Schweppenhäuser]. Frankfurt am Main: Suhrkamp Verlag, 1991, volumes II e III.

COUTINHO, Sylvia de Souza e Silva Ribeiro. O conceito de formalismo e arquitetura moderna: contribuição para uma revisão crítica da obra de Oscar Niemeyer. Rio de Janeiro: PUC-RJ, 2012.

DVOŘÁK, Max. "Alois Riegl". In: Mitteilungen der k. k. Zentral-Kommission für Erforschung und Erhaltung der Kunst- und historischen Denkmale, Volume. 4, 1905, p. 255. Disponível em: $\quad$ http://www.archive.org/stream/mitteilungenser3vol4kkze\#page/n179/mode/2up. Acesso em: 04 abr. 2019.

FIEDLER, Konrad. Schriften über Kunst. Köln: DuMont, 1977.

MÄNNIG, Maria. PFEFFER, Alexandra. (eds.) Nkf - Neue Kunstwissenschaftliche Forschungen

SCHAPIRO, Meyer. Kunstwissenschaftliche Forschungen II. Editada por Otto Pächt. Berlin, Frankfurt, 1933. Disponível em: 
https://www.collegeart.org/pdf/artbulletin/Art\%20Bulletin\%20Vol\%2018\%20No\%202\%20Sc hapiro.pdf. Acesso em: 25 abr. 2019.

Recebido em: 30/04/2019

Aceito em: 26/06/2019 